\title{
UMA POLÍTICA PÚBLICA DE TRATAMENTO DO CONFLITO COMO FORTALECIMENTO DA CIDADANIA ${ }^{1}$
}

\author{
Luthyana Demarchi de Oliveira² \\ Fabiana Marion Spengler ${ }^{3}$
}

\section{SUMÁRIO}

1 Introdução. 2 Delineamentos do sistema estatal 3 A definição de política pública $4 \mathrm{~A}$ crise de jurisdição 4 . A nova política pública brasileira de tratamento do conflito. 5. A nova política pública brasileira como meio de fortalecimento da cidadania 6 Considerações Finais. 7 Referências.

\section{RESUMO}

O presente artigo científico tem como objetivo delinear alguns pontos da crise no sistema estatal e de jurisdição, em especial, o brasileiro, bem como apresentar ante a situação de crise, a definição de políticas públicas. Nesse sentido, a implementação das políticas públicas estabelece ações e metas que vão nortear o tratamento de muitos problemas sociais. Desse modo, a política pública de tratamento do conflito, instituída pela Resolução n‥ 125 do Conselho Nacional de Justiça, consolida-se apresentando mecanismos consensuais como a mediação e a conciliação que vem contribuindo para a construção de um novo paradigma de sistema voltado para a pacificação social. Frente a esse contexto, analisa-se, ainda, a participação entre sociedade e Estado, de modo conjunto e cooperativo, transformando os contornos da crise do mundo globalizado de modo a promover a cidadania e a democracia participativa.

Palavras-chave: Cidadania. Estado. Política Pública. Sistema. Tratamento do Conflito.

\section{INTRODUÇÃO}

O mundo moderno ainda sofre as conseqüências do sistema capitalista globalizado e os conflitos existentes são resultados, em sua maioria, da crise do sistema estatal. O Estado começa desse modo, a se reestruturar conjugando esforço de seus principais atores, como o objetivo de burlar a crise. Nesse sentido, a participação da sociedade e o fortalecimento da cidadania são os caminhos encontrados para enfrentar muitos problemas.

Os problemas se dão nas esferas econômicas e sociais, estimulado pelo mercado que controla a ordem mundial. Os efeitos são devastadores reduzindo os direitos sociais e promovendo os interesses do mercado.

Contudo, contrariando esse contexto, nascem alguns instrumentos de defesa/superação, denominados de políticas publicas. As políticas públicas são 
ações ou programas instituídos pelo Estado, de modo a enfrentar determinada situação problemática ou conflituosa, e objetivando a garantirem direitos e a participação dos cidadãos.

No mesmo contexto de crise, explodem os conflitos sociais, principalmente pela garantia dos direitos. Essa explosão perpassa também pelo sistema jurisdicional que não consegue responder os litígios demandados, resultado da morosidade da prestação jurisdicional, do acúmulo de ações, bem como da falta de servidores e magistrados e do paradigma de guerra instalado.

Nesse sentido, o Conselho Nacional de Justiça (CNJ), órgão instituído com a finalidade específica de zelar e planejar, através de metas e programas pelo serviço de prestação jurisdicional, cumulou a função de formular políticas públicas de acesso e prestação da justiça, de modo eficiente e efetivo em benefício à sociedade.

Dessa forma, através da Resolução ํo. 125, o Conselho institui a Política Judiciária Nacional de Tratamento Adequado de Interesses, no âmbito do poder judiciário, de modo a incentivar e adotar mecanismos consensuais de tratamento do conflito.

Por meio de Resolução, estipulam-se a mediação e a conciliação como mecanismos de solução e tratamento do conflito. O presente estudo faz uma análise da importância dessa política para o sistema, traçando através da pesquisa bibliográfica o alcance desses mecanismos para a sociedade.

Assim, a implementação da política pública de tratamento ${ }^{4}$ adequado dos conflitos, além de tornar efetivo o principio constitucional de acesso à justiça (art. 5o, XXXV da Constituição Federal) e a outros direitos, contribui para a construção de um novo paradigma para o sistema, ou seja, a pacificação social.

Nesse mesmo sentido, a implementação da política publica contribui para o fortalecimento da cidadania, promove a cooperação e a confiança entre Estado e sociedade e estimula a Democracia participativa.

\section{DELINEAMENTOS DO SISTEMA ESTATAL}

Os conflitos de permeiam a sociedade moderna é resultado de uma serie de fatores que englobam o sistema. O sistema pode ser conceituado como "toda a organização complexa que recolhe e transmite informação, gera atividades e controla resultados, dotado de certa autonomia, mas permanentemente articulado ao contexto" ${ }^{5}$.

O sistema de organização de uma sociedade perpassa por elementos como o Estado, governo, poder, economia e cidadãos. Nesse sentido, o Estado é o resultado de um processo histórico de concentração de poder que ocorre na Europa, entre o final da Idade Média e o inicio da Idade Moderna. Nas palavras da Rodrigues, "o Estado moderno se constitui de um conjunto de 
instituições publicas que envolvem múltiplas relações com o complexo social num território delimitado" 6 .

O governo é a instituição formada por indivíduos e instituições que tem como função orientar os rumos da sociedade. O elemento poder é definido como a capacidade de influenciar e exigir da sociedade determinada ação ou conduta. É encontrado em várias esferas, e é característica da coerção do Estado, ou seja, para que o Estado exija o cumprimento de determinadas regras pode lançar mão do seu poder coercitivo. Nas palavras de Höfling:

\begin{abstract}
Torna-se importante aqui ressaltar a diferenciação entre Estado e governo. Para se adotar uma compreensão sintética compatível com os objetivos deste texto, é possível se considerar Estado como o conjunto de instituições permanentes - como órgãos legislativos, tribunais, exército e outras que não formam um bloco monolítico necessariamente - que possibilitam a ação do governo; e Governo, como o conjunto de programas e projetos que parte da sociedade (políticos, técnicos, organismos da sociedade civil e outros) propõe para a sociedade como um todo, configurando-se a orientação política de um determinado governo que assume e desempenha as funções de Estado por um determinado período ${ }^{7}$.
\end{abstract}

O governo tem o poder político de tomar decisão de acordo com a preferência e interesses de diversos atores. Quando os indivíduos são eleitos para tomarem as decisões, tem-se um governo democrático. Normalmente, as tarefas e ações do Estado são executadas pela Administração Pública.

A economia é uma instancia autônoma e dependente que está intimamente ligada ao mercado que, normalmente, tem ditado as regras. Nesse sentido, relembrar esses termos nos leva conseqüentemente, a palavra crise. A crise está afetando a maioria das sociedades do mundo, desde que se preconizou a idéia de diminuição da intervenção do estado em oferecer os direitos sociais à população.

Nas explicações de Rodrigues, o Estado passa por transformações históricas que acarretam não só a organização burocrática do Estado, mas também do reordenamento jurídico da sociedade com o reconhecimento dos direitos do cidadão. Para a autora, em primeiro lugar, a organização burocrática do Estado nasce da administração pública que é composta do conjunto das atividades ou ações do Estado, definidas por lei ou pelos atos do governo, visando à execução de interesse público. O reordenamento da sociedade se dá pelo Estado de Direito que é "um sistema jurídico que garanta as liberdades fundamentais, com a aplicação da lei por intermédio de juízes independentes" e por fim, um sistema de proteção social que "garanta renda mínima, saúde, educação, habitação, saneamento e segurança como direitos de todo cidadão, nascendo, assim o Estado de Bem-Estar Social (Welfare State) ${ }^{8}$.

Assim, o Estado de Bem-Estar Social é um sistema de proteção social que emergiu nos países de capitalismo desenvolvido no período do pósSegunda Guerra Mundial. Contudo, contrariando a essa idéia de Estado de Bem-Estar Social e implementando a bandeira neoliberal que percorria as sociedades modernas, o postulado de Estado Mínimo, nasce com o objetivo 
claro que o mercado coordenasse a economia. A idéia é afastar a intervenção estatal do mercado, buscando a auto-regulação e oportunizando a livre atividade econômica de acordo com os interesses privados e da economia globalizada ${ }^{9}$.

O Estado brasileiro, particularmente, é centralizador. Assumiu, por tradição, muito mais objetivos econômicos, que da proteção social e do bemestar. Dessa forma, adquiriu uma postura de Estado fazedor e não regulador, ou seja, protegia determinados direitos ao invés de dialogar com a sociedade civil um espaço político. Nesse sentido para Bacelar: "Estado centralizador, em muitos momentos da nossa vida recente, se junta ao autoritário: tivemos uma longa ditadura no período Vargas e, depois, uma longa ditadura nos governos militares pós-64. Então, o viés autoritário é muito forte nas políticas públicas do país".

Observa-se, que o Estado brasileiro era regulador e desenvolvimentista implementado pelas classes dominantes. O objetivo principal era a industrialização e o crescimento econômico e o Estado de bem estar social estava bem distante. Nesse sentido explica Bacelar:

\begin{abstract}
Desde o começo do século, optou-se pela industrialização. A grande tarefa era consolidar esse processo e fazer do Brasil uma grande potência. Assim, o grande objetivo era de ordem econômica: construir uma potência intermediária no cenário mundial. $O$ Estado desempenhava a função de promover a acumulação privada na esfera produtiva. O essencial das políticas públicas estava voltado para promover o crescimento econômico, acelerando o processo de industrialização, o que era pretendido pelo Estado brasileiro, sem a transformação das relações de propriedade na sociedade brasileira ${ }^{10}$.
\end{abstract}

Verifica-se, assim, pelo histórico brasileiro que há um distanciamento entre Estado e sociedade, já que pelos ideais do neoliberalismo preconiza o Estado Mínimo que defende o individualismo evitando a interação social. Nesse sentido, ainda persiste, uma imagem negativa e minimalista do Estado, resultado do descrédito com relação ao Estado e à Administração Pública. Esse descrédito diz respeito à ação estatal como um todo, às diversas políticas públicas, e aos políticos, de um modo geral. Da mesma forma, a ocorrência de práticas de cunho clientelista e marcadas pela corrupção, após a democratização dos anos 80, e a maior visibilidade desses fenômenos, decorrente da própria democratização, articularam-se à onda minimalista de corte neoliberal, que propõe a redução radical do Estado, contaminando a visão que os cidadãos têm da ação governamental e da Administração Pública em todas as esferas de governo ${ }^{\uparrow 1}$.

Desse modo, a fim de evitar um colapso mundial, organizações de sociedade civil começam a tomar iniciativas pontuais com o objetivo de burlar 0 quadro de crise e garantir, assim, os direitos de todos os cidadãos. Na busca desse espaço de diálogo, a sociedade civil, ressurge como a esfera de interação, de modo a garantir a autonomia da economia e do Estado. A construção dessa esfera torna-se assim, essencial enquanto participação política e social dos cidadãos. Nesse sentido, o combate do modelo liberal, denominado democracia liberal se dá pela instituição de uma democracia REVISTA DO DIREITO UNISC, SANTA CRUZ DO SUL No 35|P. 03-18| JAN-JUN 2011 
participativa com espaços estruturais de integração social. Nas palavras de Souza:

\begin{abstract}
No processo, o próprio espaço político liberal, o espaço da cidadania sofre uma transformação profunda. A diferenciação das lutas democráticas pressupõem a imaginação social de novos exercícios de democracia e de novos critérios democráticos para avaliar as diferentes formas de participação política. $E$ as transformações prolongam-se no conceito de cidadania, no sentido de eliminar os novos mecanismos de exclusão da cidadania, de combinar formas individuais com formas coletivas de cidadania e, finalmente, no sentido de ampliar esse conceito para além do princípio da reciprocidade e simetria entre direitos e deveres ${ }^{12}$.
\end{abstract}

Nas afirmações de Morin "os gigantescos problemas da civilização, demandando mobilização para humanizar a burocracia e a técnica, defender e desenvolver as convivialidades e solidariedades"13. Assim, a sociedade contemporânea, colhendo os resultados negativos do modelo de progresso capitalista, necessita a reaprender a viver conjugando as formas individuais e coletivas de cidadania, de modo a tratar seus conflitos.

Nesse sentido, o sistema estatal não é somente uma organização burocrática, mas também um reordenamento jurídico, social e político da sociedade com o reconhecimento da cidadania. Assim, o papel do Estado é promover políticas que priorizem a convivência dos cidadãos, de modo a multiplicar os espaços públicos de cooperação e participação, como serão analisados a seguir.

\title{
2 A DEFINIÇÃO DE POLÍTICA PÚBLICA
}

A política publica normalmente é um conjunto de ações ou programa instituído pelo bem ou interesse comum. "O conceito tem ligação direta com a "política" que advém da palavra de origem grega polis, que se refere às coisas da cidade, ou seja, "ao que é urbano, público, civil e social" ${ }^{14}$.

Aristóteles, no século 4⿳亠口冋.C, foi o primeiro filósofo a desenvolver um tratado sobre o tema. $\mathrm{O}$ autor referia-se que a política era a arte ou ciência do Governo e apresentava uma tipologia das formas de governar. Na era moderna, a idéia de política começa a ser substituída como "ciência do Estado" ou" ciência política", que dizia respeito à "atividade ou ao conjunto de atividades que, de alguma maneira, faz referência ao Estado. Como tal, o conceito de política está estreitamente vinculado ao de poder" ${ }^{15}$. Reitera, ainda, a política é: "um conjunto de procedimentos que expressam relações de poder e que se orienta à resolução de conflitos no que se refere aos bens públicos. Em uma palavra, a política implica a possibilidade de resolvermos conflitos de uma forma pacífica"

Para a maioria da doutrina os aspectos conceituais das políticas públicas envolvem três dimensões: a institucional denominada de "polity", ordenado pelo sistema político e delineado pelo sistema jurídico; a processual "politics" que se dá pela dinâmica da política e da competição do poder; e a material "policy" 
que envolve o conteúdo concreto dita como o "Estado em ação". Salienta-se que as três esferas são permanentes e se influenciam reciprocamente.

Não existe uma única e nem "a melhor" definição de política pública. Dessa forma, observa-se que várias são as definições, sendo um processo pelo qual os diversos atores que compõem a sociedade tomam decisões coletivas que objetivam um interesse comum. Nas palavras de Schimidt:

\begin{abstract}
configuram decisões de caráter geral que apontam rumos e linhas estratégicas de atuação governamental, reduzindo os efeitos da descontinuidade administrativa e potencializando os recursos disponíveis ao tornarem públicas, expressas e acessíveis a população e aos formadores de opinião as intenções do governo no planejamento de programas, projetos e atividades
\end{abstract}

Normalmente, a política pública é gerada por uma situação de dificuldade ou por algum problema, que chama a atenção do Estado, aqui envolvendo todos os atores de forma ampla, na qual é inserido numa agenda política. Assim, há a formulação da política pública que é a definição sobre a maneira de solucionar o problema político em pauta e a escolha das alternativas a serem adotadas. A próxima fase é a de implementação da concretização da formulação, através de ações e atividades que materializam as diretrizes, programas e projetos, e está a cargo do aparelho burocrático (administração). E por último se dá sua avaliação, na qual é a analisada seus resultados, custos e aceitação pelos cidadãos.

Desse modo, ampliando a conceituação Souza ${ }^{16}$ explica que as políticas públicas em geral ou aquelas denominadas sociais, são campos multidisciplinares que focalizam as explicações sobre a natureza e o processo, sendo que uma teoria geral da política pública implica na mescla de teorias construídas em outros campos como da sociologia, da ciência política e da economia. Para a autora uma teoria da política pública precisa também explicar as inter-relações entre Estado, política, economia e sociedade, já que ambas as instituições "partilham um interesse comum na área e têm contribuído para avanços teóricos e empíricos" ${ }^{17}$.

Nesse sentido, a definição de políticas públicas permeia um campo de estudo que vem trazendo importantes contribuições para compreender 0 funcionamento das instituições e das complexidades que envolvem a vida nos dias atuais. Assim, a seguir passa-se a uma breve análise da crise da jurisdição, instituição responsável pela resolução dos conflitos da sociedade.

\title{
3 A CRISE DE JURISDIÇÃO
}

O advento da Constituição Federal de 1988, também conhecida como Constituição Cidadã trouxe a garantia de direitos a todos os cidadãos, fazendo com que os esses tivessem um maior acesso e maior participação com os entes estatais. Nesse contexto, a todo o cidadão brasileiro é garantido o acesso à justiça, bem como aos instrumentos que garantam seus direitos. Nas palavras de Cappelletti e Garth "O acesso à justiça pode, portanto, ser 
encarado como o requisito fundamental - o mais básico dos direitos humanos de um sistema jurídico moderno e igualitário que pretenda garantir, e não apenas proclamar os direitos de todos" 18 .

A abertura das portas do Judiciário é o resultado do crescimento da população mundial que sofre com o aumento dos conflitos econômicos ou sociais que começam a permear as sociedades. Nesse sentido:

A proliferação dos conflitos tem direita relação com o aumento populacional, que é inevitável. Com a tendência universal de ampliação do acesso à justiça, sentida no Brasil, notadamente a partir do advento da Constituição da República de 1988, conhecida como Constituição Cidadã, sintomaticamente, houve uma redescoberta da justiça pelo cidadão

O acesso ao Judiciário torna-se, assim, um direito para o cidadão, fazendo com que cresça o número das demandas. A população corre em busca de uma solução para seus problemas, contudo frente à estrutura arcaica do sistema começam a aparecer os primeiros problemas.

Assim, o aumento crescente do ajuizamento das ações começa a gerar acúmulos enormes nos Cartórios, fazendo que cresça igualmente a quantidade de trabalho, sem aumentar o número de pessoas para dar suporte ao aparelho. Nessa situação, acontece ainda o acúmulo no trabalho dos magistrados que dobram também o tempo na realização das audiências e conseqüentemente, não conseguem agilizar e fundamentar suas decisões. O quadro piora quando as ações coletivas não conseguem mais dar respostas à população em geral e há a reiterada prática de interposição de recursos de decisões já pacificadas no sentido protelatório de ganhar tempo.

Contribuindo, ainda, para a situação, há o acúmulo de instâncias, a falta de preparo dos operadores, bem como dos servidores e magistrados frente aos mecanismos de agilidade dos procedimentos judiciais, o escasso orçamento dedicado à máquina judiciária e conseqüentemente, a demora e a descredibilidade da prestação jurisdicional. Estes são os problemas que completam a crise instaurada no sistema de justiça brasileiro.

Normalmente, tem-se a jurisdição como sendo aquela autoridade estatal (Juiz), encarregado de resolver o conflito dos cidadãos, sendo que nesse sistema, para se ter "justiça", tem-se um ganhador e um perdedor, ou seja, há uma cultura que "privilegiou o paradigma ganhar-perder, que funciona com uma lógica determinista binária, na qual a disjunção e a simplificação limitam as opções possíveis" 19 .

Nesse sentido explica Spengler:

A justiça consensual surge como resposta ao disfuncionamento do modelo judiciário tradicional, resgatando um modo de regulação social que embora possa ser percebido como um instrumento de integração apresenta-se como um procedimento geralmente informal, através do qual um terceiro busca promover a comunicação e, conseqüentemente, as trocas entre as partes, possibilitando que as mesmas se confrontem, em igualdade de posições, buscando 0 
consenso. Essa busca pelo consenso ocorre mediante a apropriação, pelas partes, do poder de tratar seus conflitos ${ }^{20}$.

Desse modo, frente a esse quadro de crise iniciou-se um processo de reforma da justiça em que o paradigma cultural do litígio volta-se para a consensualidade, para o tratamento do conflito em busca da pacificação social. Frente a essa perspectiva começa a ser implementada no país uma nova política pública de tratamento dos conflitos.

\title{
4 A NOVA POLÍTICA PÚBLICA BRASILEIRA DE TRATAMENTO DE CONFLITO
}

O quadro de crise do sistema exigiu do Estado reformas de modo a garantir e assegurar o princípio de acesso à justiça dos cidadãos. Nesse sentido, cria a através da emenda constitucional no. 45 de 30 de dezembro de 2004, que inclui no art.103-B da Constituição Federal, o Conselho Nacional de Justiça que é o órgão encarregado de desenvolver ações e programas com o objetivo de garantir o controle administrativo e processual, a transparência e o bom funcionamento do Judiciário.

Dessa forma, dentre as múltiplas funções do Conselho Nacional de Justiça, estipula-se a implementação de ações de reforma do sistema de justiça, instituindo, assim, uma política de tratamento adequado dos conflitos, através da Resolução №. 125 de novembro de 2010.

A política pública, normalmente, é instituída tendo como base conceitual os problemas da esfera pública. Nesse sentido, explica Schimidt:

\begin{abstract}
Ou seja, diz respeito ao plano das questões coletivas, da polis [...]. O termo política pública é utilizado com significados algo distinto, com uma abrangência maior ou menor: ora indica um campo de atividade, ora um propósito político bem concreto, ou um programa de ação ou os resultados obtidos por um programa [...] em uma política há sempre uma teia de decisões e ações que alocam (implementam) valores; uma instância que, uma vez constituída, vai conformando o contexto no qual as decisões futuras serão tomadas; e, mais do que uma única decisão, o envolvimento e uma teia de decisões e o desenvolvimento de ações no tempo ${ }^{21}$.
\end{abstract}

Dessa forma, ampliando a abrangência da política, conforme os termos da Resolução №. 70, de 18 de março de 2009, do próprio Conselho, estipula-se que a eficiência operacional, o acesso ao sistema de Justiça e a responsabilidade social serão os objetivos estratégicos do Poder Judiciário e que 0 direito de acesso á justiça, conforme o previsto no art. 5ㅇ, XXXV, da Constituição Federal, implicará também a ordem jurídica justa. Para Baccelar, a finalidade do Poder Judiciário é a "pacificação social e, portanto, independentemente do processo e do procedimento desenvolvido para a resolução dos conflitos no âmbito do que se denomina monopólio jurisdicional, também cabe ao Judiciário incentivar mecanismos e técnicas que mais se aproximem o cidadão da verdadeira Justiça" ${ }^{22}$. 
A justificativa de implementação da política pública considera o largo e crescente aumento dos problemas e conflitos jurídicos na sociedade, de forma a organizar e consolidar, em âmbito nacional, não somente os serviços prestados nos processos judiciais, como também de outros mecanismos de solução de conflitos, em especial os consensuais, como a mediação e a conciliação. Assim, "desenvolvem-se novas políticas sociais referentes ao papel jurisdicional do Estado frente a essa explosão de litigiosidade, decorrente da complexidade socioeconômica moderna"23.

A Resolução n. 125, de 29 de novembro de 2010, do Conselho Nacional de Justiça estipula uma política publica de tratamento adequado dos conflitos de interesse, assegurando a todos à solução dos conflitos por meios adequados, atendendo sua natureza e peculiaridade. (art. $1^{\circ}$ ).

O objetivo desse artigo é assegurar que todos os cidadãos tenham atendimento e orientação ao seu problema, oferecendo mecanismos de tratamento de controvérsias, em especial os denominados consensuais, como a mediação e a conciliação e não havendo resultado assegurar a solução mediante sentença do órgão judiciário.

A implementação da política, priorizando a qualidade dos serviços e à disseminação da cultura de pacificação social, deverá priorizar a centralização das estruturas judiciárias, formação e treinamento adequado aos servidores, conciliadores e mediadores e acompanhamento estatístico específico.

No art. 4ํำ da Resolução reitera-se, uma das atribuições do Conselho Nacional de Justiça, de promover ações de incentivo à autocomposição de litígios e à pacificação social por meio da conciliação e da mediação, prevendo a implementação do programa com a participação de uma rede de todos os órgãos do Poder Judiciário, bem como pelas entidades públicas e privadas parceiras e as entidades de ensino.

A Resolução menciona a conciliação e a mediação como instrumentos efetivos de pacificação social, de modo a solucionar e prevenir os litígios, já que sua prática em programas já implementados no país tem reduzido à excessiva judicialização dos conflitos de interesses, a quantidade de recursos e de execução de sentenças, devendo servir de base para a criação de Juízos de resolução alternativo de conflitos, verdadeiros órgãos judiciais especializados na matéria. Assim, a idéia é "trabalhar com a solução pacífica e negociada portanto, mais preventiva do que curativa - dos problemas que surgem na sociedade, visando à estrutura de um processo de formação de pacificação social no âmbito das lides- judicializadas ou não"24.

Por fim, estabelece ainda a relevância e a necessidade de organizar e uniformizar os serviços de conciliação, mediação e outros métodos consensuais de solução de conflitos, para evitar disparidades de orientação e práticas, bem como para assegurar a boa execução da política pública. Nesse sentido, a seguir passa-se a analisar a política pública como fortalecimento da cidadania. 


\title{
5 A NOVA POLÍTICA PÚBLICA BRASILEIRA COMO MEIO DE FORTALECIMENTO DA CIDADANIA
}

A implementação de uma política publica é o instrumento utilizado para a promoção da cidadania. Percebe-se, que a cada ano os problemas aumentam, a expansão tecnológica e econômica, conseqüência do mundo globalizado, espalha-se pelo mundo. Frente a essa situação, conseqüentemente, também aumentam os problemas sociais considerados graves, como a pobreza, a miséria, o desemprego e a exclusão social.

Assim:

\begin{abstract}
"O processo de globalização em desenvolvimento atinge todas as sociedades. (...) Também a consenso que a forma atual de globalização cria desemprego e exclusão social, causando danos econômicos-sociais e ambientais. Desencadeia violências de todo tipo. (...) Vale salientar que a pressão da globalização para baixo cria a necessidade do governo buscar alternativas novas do contato direto com os cidadão superando o ortodoxo de fazer política. De igual maneira, a cidadania conscientemente organizada necessita criar mecanismo de contato e controle de políticas estatais, democratizando-as. Isso demanda novos experimento de participação política direta de maior número possível de cidadãos. Assim, um dos maiores desafio da globalização é a discussão profunda e ampla a cerca de uma política da condição social humana global| ${ }^{25}$.
\end{abstract}

Dessa forma, os muitos danos causados pela globalização trouxeram problemas de todas as ordens, sejam econômicos, ambientais, e principalmente sociais, que acarretam conflitos nas diversas relações da sociedade. Nesse sentido, as políticas públicas nascem com o objetivo de fortalecimento da cidadania e como uma alternativa pacífica de tratamento dos conflitos sociais.

Observa-se que é fundamental para o Estado garantir os direitos individuais e coletivos, para a construção de uma sociedade livre que propicie 0 desenvolvimento social, o bem-estar e erradicação da pobreza. Para Leal, a concretização do Estado Democrático de Direito que tem como objetivo "assegurar o exercício dos direitos sociais e individuais, a liberdade, a segurança, o bem-estar, o desenvolvimento, a igualdade e a justiça, como valores supremos de uma sociedade fraterna, pluralista e sem preconceitos" ${ }^{26}$.

Vale ressaltar que muitos desses direitos não tiveram sua efetiva aplicabilidade, devido uma série de fatores de ordem política, econômica e funcional que provocaram uma crise do Estado Democrático de Direito. Assim, a retomada desse Estado perpassa pela idéia de política dedicada a reinventar a convivência entre os cidadãos e isso depende da multiplicação de espaços sociais favoráveis à expansão de novas formas de solidariedade, cooperação e participação democrática.

Essas políticas implicam também em novas formas de tratamento dos conflitos sociais, os quais somente produzem eficácia se contarem com uma mudança de paradigma, transformando o litígio em consenso. 
Nesse sentido, o Estado Democrático de Direito, promulgado pela Constituição de 1988, passou a contar com um conjunto significativo de instrumentos de modo a enfrentar os problemas frutos das relações sociais modernas. Assim, "essa medidas deverão ser implementadas, conjuntamente, com meios assecuratórios à cidadania, pois a crise que enfrentamos provém de causas distintas pertencentes a um mesmo fenômeno global, mas com características próprias" 27.

O objetivo maior dessa política é pressionar e reclamar uma prestação jurisdicional célere e eficaz, capaz de tratar os conflitos decorrentes das relações sociais e luta para aproximação da jurisdição e da cidadania, para que coloque em prática a questão de acesso à justiça.

Desse modo, o que se almeja é um Estado participativo que se aproxime do seu cidadão e busque a defesa das questões sociais, priorizando a inclusão social através da valorização da cidadania e da participação.

Nesse sentido, como defende Kliksberg o “'Estado Inteligente', não é nem um Estado maximalista, nem minimalista, mas deve ter como objetivo a ampliação do capital social, promovendo as conexões entre as forças atuantes na sociedade" ${ }^{28}$. Esse Estado é permeado pela transparência, descentralização e participação popular.

Assim, o capital social, também pode ser entendido como o recurso que as pessoas possuem para acessarem outros recursos socialmente valorizados em virtude das suas relações. Nas explicações de Schmidt é "um conjunto de redes, relações e normas que facilitam ações coordenadas na resolução de problemas coletivos e que proporcionam recursos que habilitam os participantes a acessarem bens, serviços e outras formas de capital" 29 .

Portanto, o capital social favorece a construção de uma democracia, já que ele reside nas classes econômicas menos favorecidas, através dos vínculos entre as pessoas. $\mathrm{E}$ é através desses vínculos que se fortalece a cooperação, que gera a confiança. A atuação conjunta do Estado e da sociedade fomenta essa confiança. Desse modo "da capacidade do Estado (pelos diversos Governos) para executar política públicas sociais mais eficazes, abrangentes e universais, depende o aprimoramento do bem estar e da cidadania, com a diminuição das desigualdades e a consolidação da democracia de cidadãos e cidadãs" ${ }^{30}$.

Nesse sentido, a atuação conjunta entre Estado e sociedade fomenta a confiança e propicia o fortalecimento da dita democracia participativa, que busca incessantemente espaços públicos destinados a políticas públicas de bem estar e de pacificação social.

\section{CONSIDERAÇÕES FINAIS}

O quadro de crise resultou um processo de reforma no sistema estatal e jurisdicional, em que a adoção de políticas públicas foi o mecanismo 
encontrado para enfrentar os problemas e conflitos jurídicos advindos das sociedades modernas.

Diante da descredibilidade e da demora da prestação judicial, cria-se um órgão de controle administrativo e processual cuja função é assegurar a transparência, a eficiência e o bom funcionamento dos órgãos judiciários no País, denominado de Conselho Nacional de Justiça.

Dentre suas múltiplas funções está de promover ações e programas de reforma do sistema de justiça. Nesse sentido, implementa, através da Resolução no. 125, uma Política Judiciária Nacional de Tratamento Adequado de Conflito.

Desse modo, o paradigma cultural do litígio, transforma-se ao poucos para aquele da consensualidade, pretendendo aproximar o cidadão de uma verdadeira justiça. A política estipula, então, a conciliação e a mediação como os mecanismos consensuais para o tratamento do conflito.

Consequentemente, a implementação de uma política nacional de tratamento dos conflitos, através de mecanismos consensuais, como a conciliação e a mediação, transforma as relações não só dos envolvidos, mas contribui e muito para a mudança de paradigma de um sistema voltado para a pacificação social.

Nesse sentido, a política publica contribui também para o fortalecimento da cidadania, buscando resgatar sentimentos de cooperação e a confiança entre Estado e sociedade, os quais foram totalmente destruídos pelas conseqüências devastadoras do mundo capitalista globalizado.

Assim, o resgate dessas relações e o estímulo pela participação social serve como meio de ampliação do capital social e como forma de inclusão social, objetivos inerentes à democracia participativa.

\section{A PUBLIC POLICY FOR TREATMENT OF CONFLICT AS STRENGTHENING OF CITIZENSHIP}

\section{ABSTRACT}

This research paper aims to outline some points of crisis in the state and jurisdiction, in particular Brazil, as well as appear before the crisis, the definition of public policies. In this sense, the implementation of public policy establishes actions and goals that will guide the treatment of many social problems. Thus, public policy treatment of the conflict established by Resolution ㄲo. 125 of the Conselho Nacional de Justiça, is consolidated featuring consensual mechanisms such as mediation and conciliation that has contributed to the construction of a new paradigm of systems for the social peace. With this context, analyze also the participation of society and state, so cooperatively 
together and transforming the contours of the crisis of the globalized world in order to promote citizenship and participatory democracy.

Keywords: State. Public Policy. Treatment of Conflict. System. Citizenship.

\section{NOTAS}

1. O presente texto foi elaborado a partir de pesquisa realizada junto ao projeto intitulado Multidoor courthouse system - avaliação e implementação do sistema de múltiplas portas (multiportas) como instrumento para uma prestação jurisdicional de qualidade, célere e eficaz financiado pelo CAPES/CNJ do qual são pesquisadoras as duas autoras.

2. Mestranda em Direito pela Universidade de Santa Cruz. Bolsista CAPES/CNJ junto ao projeto Multidoor courthouse system - avaliação e implementação do sistema de múltiplas portas (multiportas) como instrumento para uma prestação jurisdicional de qualidade, célere e eficaz. Especialista em Direitos Humanos pelo Instituto de Filosofia Berhier/ Passo Fundo/RS. Especialista em Direito Civil pela Imed/Passo Fundo/RS. Pesquisadora do Grupo de Estudos "Políticas Públicas no Tratamento dos Conflitos" vinculado ao CNPQ. Advogada. Endereço eletrônico: luthyoliveira@hotmail.com. Currículo lattes: http://lattes.cnpq.br/2903682177640016

3. Pós-Doutora pela Università degli Studi di Roma Tre/Itália, com financiamento (bolsa PDE) do CNPq. Doutora em Direito pelo programa de Pós-Graduação stricto sensu da Universidade do Vale do Rio dos Sinos - UNISINOS - RS; mestre em Desenvolvimento Regional, com concentração na área Político Institucional da Universidade de Santa Cruz do Sul - UNISC - RS; docente dos cursos de Graduação e Pós Graduação lato e stricto sensu da última instituição; Coordenadora do Grupo de Estudos "Políticas Públicas no Tratamento dos Conflitos" vinculado ao CNPQ; coordenadora do projeto de pesquisa "Mediação de conflitos para uma justiça rápida e eficaz" financiado pelo CNPQ (Edital Universal 2009 processo 470795/2009-3) e pela FAPERGS (Edital Recém-Doutor 03/2009, processo 0901814); pesquisadora do projeto Multidoor courthouse system - avaliação $e$ implementação do sistema de múltiplas portas (multiportas) como instrumento para uma prestação jurisdicional de qualidade, célere e eficaz financiado pelo CNJ e pela CAPES; coordenadora e mediadora judicial junto ao projeto de extensão "A crise da jurisdição e a cultura da paz: a mediação como meio democrático, autônomo e consensuado de tratar conflitos"; advogada. Endereço eletrônico: fabiana@unisc.br. Currículo lattes: http://lattes.cnpq.br/8254613355102364; Blog: http://fabianamarionspengler.blogspot.com/

4. Cabe explicar que se utilizará a expressão "tratamento" em vez de "resolução" de conflitos, justamente por entender que os conflitos sociais não são "solucionados" pelo Judiciário no sentido de resolvê-los, suprimi-los, elucidá-los ou esclarecê-los. Isto porque "a supressão dos conflitos é relativamente rara. Assim como relativamente rara é a plena resolução dos conflitos, isto é, a eliminação das causas, das tensões, dos contrastes que os originaram (quase por definição, um conflito social não pode ser "resolvido")." (BOBBIO, Norberto; PASQUINO, Gianfranco. Dicionário de política. Tradução de Carmem C. Varriale, Gaetano Lo Mônaco, João Ferreira, Luís Guerreiro Pinto Cascais e Renzo Dini. 12. ed. Brasília: Universidade de Brasília, 2004, p. 228, BOLZAN DE MORAIS, José Luiz; SPENGLER, Fabiana Marion. Mediação e arbitragem: alternativas à jurisdição. Porto Alegre: Livraria do Advogado, 2008 e SPENGLER, Fabiana Marion. Da jurisdição à mediação: por uma outra cultura no tratamento dos conflitos. Ijuí: UNIJUí (2010).Nesse sentido, a expressão "tratamento" torna-se mais adequada enquanto ato ou efeito de tratar ou medida terapêutica de discutir o conflito buscando uma resposta satisfativa.

5. SCHIMIDT, João Pedro. Para entender as políticas públicas: aspectos conceituais e metodológicos. In: REIS, Jorge Renato; LEAL, Rogério Gesta. (Org.). Direitos sociais e políticas públicas: desafios contemporâneos. Tomo 8. Santa Cruz do Sul: Edunisc, 2008, p. 2326.

6. RODRIGUES, Marta Maria Assumpção. Políticas Públicas. São Paulo: Publifolha, 2010.p.17

7. HÖFLING, Eloisa Matos. Estado e Política (Públicas) Sociais. 2001: Disponível em : http://www.scielo.br/scielo.php?pid=s0101-32622001000300003\&script=sci arttext. Acesso em: 15 jun 2011. 
8. RODRIGUES, Marta Maria Assumpção. Políticas Públicas. São Paulo: Publifolha, 2010.p.18

9. Nesse sentido explica Klisberg sobre o Estado Mínimo: [...] suas funções deveriam ser totalmente mínimas e que se deveria deixar o desenvolvimento entregue ao mercado e à "mão invisível". O Estado foi sentido como um estorvo para a dinâmica a ser impulsionada. Enfatizou-se a existência de uma autonomia entre Estado e mercado. Finalizou-se um ativo processo "demolição" do Estado nos países em desenvolvimento.[...] tratou-se, me muitas ocasiões, de privatizar e eliminar funções, no mais curto prazoKLIKSBERG apud COSTA, Marli M. M. da (Org). Direito, cidadania e política públicas II- Direito do cidadão e dever do Estado. Porto Alegre: Free Press, 2007, p. 304

10. BACELAR, Tânia. As Políticas Públicas no Brasil: heranças, tendências e desafios. Disponível em: http://www4.fct.unesp.br/grupos/gedra/textos/Texto1 politicas publicas no br TaniaBacela r.pdf. Acesso em: 16 jun 2001.

11. FARAH, Marta F. S. Parcerias, novos arranjos institucionais e políticas públicas no Brasil. Revista da Administração Pública, V. 35, №. 1, p. 119-145, jan-fev 2001.

12. SANTOS, Boaventura de Sousa apud COSTA, Marli M. M. da (Org). Diálogos entre Brasil e Espanha: da exclusão sociais aos direitos sociais. Porto Alegre: Imprensa Livre, 2008, p. 276

13. MORIN, Edgar apud COSTA, Marli M. M. da (Org). Diálogos entre Brasil e Espanha: da exclusão social aos direitos sociais. Porto Alegre: Imprensa Livre, 2008, p. 93

14. RODRIGUES, Marta Maria Assumpção. Políticas Públicas. São Paulo: Publifolha, 2010.p.13

15. RODRIGUES, Marta Maria Assumpção. Políticas Públicas. São Paulo: Publifolha, 2010,p.13

16. SOUZA, Celina. Políticas Públicas: uma revisão da literatura. Sociologias, Porto Alegre, ano 8, no. 16, jul/dez 2006. Disponível em: http://www.scielo.br/pdf/soc/n16/a03n16.pdf. Acesso em: 16 jun 2011.

17. SOUZA, Celina. Políticas Públicas: uma revisão da literatura. Sociologias, Porto Alegre, ano 8, no. 16, jul/dez 2006. Disponível em: http://www.scielo.br/pdf/soc/n16/a03n16.pdf. Acesso em: 16 jun 2011.

18. CAPPELLETTI, Mauro; GARTH, Bryant. Acesso à justiça. Porto Alegre: SAFE, 1988, p. 12.

19. SCHNITMAN, Dora Fried, LITTLEJOHN, Stephen. Novos paradigmas em mediação. Trad. Marcos A.G. Domingues e Jussara Haubert Rodrigues. Porto Alegre: Artes Médicas Sul, 1999, p.17.

20. SPENGLER, Fabiana Moraes; SPENGLER NETO, Theobaldo. Considerações sobre o tratamento de conflitos sociais: do consenso hobbesiano induzido ao consenso construído pela prática da mediação. In:REIS, Jorge Renato. LEAL, Rogério Gesta (org.). Direitos Sociais e Políticas Públicas: desafios contemporâneos. 1. Ed. Tomo 10. Santa Cruz: EDUNISC, 2010, p.3036.

21. SCHMIDT, João Pedro. Para entender as políticas públicas: aspectos conceituais e metodológicos. IN: REIS, Jorge Renato. LEAL, Rogério Gesta (org.). Direitos Sociais e Políticas Públicas: desafios contemporâneos. Tomo 8. Santa Cruz: EDUNISC, 2008, p. 2311.

22. BACCELAR, Roberto Portugal. Juizados Especiais: a nova mediação paraprocessual. São Paulo: Editora Revista dos Tribunais, 2003, p. 222.

23. MORAIS, José Luiz Bolzan de; SPENGLER, Fabiana Marion. Mediação e arbitragem: alternativa à jurisdição. 2. ed. rev. e ampl. Porto Alegre: Livraria do Advogado Editora, 2008, p.113.

24. FRAVETO, Rogério. A implantação de uma política pública. In: AZEVEDO, André Gomma (org.). Manual de Mediação Judicial. Brasília/DF: Ministério da justiça e Programa das Nações Unidas para o Desenvolvimento- PNUD. 2009, p.18.

25. VERZA, Severino Batista. As Políticas Públicas de Educação no Município. ljuí ed. UNIJUí, 2000 , p. 86.

26. LEAL, Rogerio Gesta apud COSTA, Marli M. M. da (Org). Direito, cidadania e política públicas II- Direito do cidadão e dever do Estado. Porto Alegre: Free Press, 2007, p. 304.

27. MORAIS, José Luiz Bolzan de; SPENGLER, Fabiana Marion. Mediação e arbitragem: alternativa à jurisdição. 2. ed. rev. e ampl. Porto Alegre: Livraria do Advogado Editora, 2008, p.109.

28. KLIKSBERG, Bernardo apud COSTA, Marli M. M. da (Org). Direito, cidadania e política públicas II- Direito do cidadão e dever do Estado. Porto Alegre: Free Press, 2007, p. 305. 
29. SCHMIDT, João Pedro. Exclusão, Inclusão e Capital Social: O capital social nas ações de exclusões. IN: REIS, Jorge Renato. LEAL, Rogério Gesta (org.). Direitos Sociais e Políticas Públicas: desafios contemporâneos. Tomo 9. Santa Cruz: EDUNISC, 2009, p.1560.

30. RODRIGUES, Marta Maria Assumpção. Políticas Públicas. São Paulo: Publifolha, 2010, p. 79.

\section{REFERÊNCIAS}

AZEVEDO, André Gomma (org.). Manual de Mediação Judicial. Brasília/DF: Ministério da justiça e Programa das Nações Unidas para o DesenvolvimentoPNUD. 2009.

BACELAR, Tânia. As Políticas Públicas no Brasil: heranças, tendências e desafios. Disponível em: http://www4.fct.unesp.br/grupos/gedra/textos/Texto1_politicas_publicas_no_br_ TaniaBacelar.pdf. Acesso em: 16 jun 2001.

BACCELAR, Roberto Portugal. Juizados Especiais: a nova mediação paraprocessual. São Paulo: Editora Revista dos Tribunais, 2003.

A mediação no contexto dos modelos consensuais de resolução dos conflitos. São Paulo: Revista do Processo, n. 95, p. 122-134, jul./se.1999, v. 24.

CAPPELLETTI, Mauro; GARTH, Bryant. Acesso à justiça. Porto Alegre: SAFE, 1988.

COSTA, Marli M. M. da (Org). Diálogos entre Brasil e Espanha: da exclusão sociais aos direitos sociais. Porto Alegre: Imprensa Livre, 2008, p. 276

COSTA, Marli M. M. da (Org). Direito, cidadania e política públicas II- Direito do cidadão e dever do Estado. Porto Alegre: Free Press, 2007.

FARAH, Marta F. S. Parcerias, novos arranjos institucionais e políticas públicas no Brasil. Revista da Administração Pública, V. 35, №. 1, p. 119-145, jan-fev 2001.

HÖFLING, Eloisa Matos. Estado e Política (Públicas) Sociais. Disponível em : http://www.scielo.br/scielo.php?pid=s0101-

32622001000300003\&script=sci_arttext. Acesso em: 15 jun 2011.

EGGER, Ildemar. Cultura da Paz e Mediação: uma experiência com adolescentes. Florianópolis: Fundação Boiteux, 2008.

MOORE, Christopher. O processo de mediação: estratégias práticas para a resolução de conflitos. Trad. Magda França Lopes. 2. Ed. Porto Alegre: Artmed, 1998. 
MORAIS, José Luiz Bolzan de; SPENGLER, Fabiana Marion. Mediação e arbitragem: alternativa à jurisdição. 2. ed. rev. e ampl. Porto Alegre: Livraria do Advogado Editora, 2008.

RODRIGUES, Marta Maria Assumpção. Políticas Públicas. São Paulo: Publifolha, 2010.

SPENGLER, Fabiana Moraes; SPENGLER NETO, Theobaldo. Considerações sobre o tratamento de conflitos sociais: do consenso hobbesiano induzido ao consenso construído pela prática da mediação. In: REIS, Jorge Renato. LEAL, Rogério Gesta (org.). Direitos Sociais e Políticas Públicas: desafios contemporâneos. 1. Ed. Tomo 10. Santa Cruz: EDUNISC, 2010.

SLAIB FILHO, Nagib. Reforma da Justiça: (notas à emenda constitucional ํㅡ․ 45, de 8 de dezembro de 2004). Niterói/RJ: Impetus, 2005.

SCHMIDT, João Pedro. Para entender as políticas públicas: aspectos conceituais e metodológicos. IN: REIS, Jorge Renato. LEAL, Rogério Gesta (org.). Direitos Sociais e Políticas Públicas: desafios contemporâneos. Tomo 8. Santa Cruz: EDUNISC, 2008.

Exclusão, Inclusão e Capital Social: O capital social nas ações de exclusões. IN: REIS, Jorge Renato. LEAL, Rogério Gesta (org.). Direitos Sociais e Políticas Públicas: desafios contemporâneos. Tomo 9. Santa Cruz: EDUNISC.

SCHNITMAN, Dora Fried, LITTLEJOHN, Stephen. Novos paradigmas em mediação. Trad. Marcos A.G. Domingues e Jussara Haubert Rodrigues. Porto Alegre: Artes Médicas Sul, 1999.

SOUZA, Celina. Políticas Públicas: uma revisão da literatura. Sociologias, Porto Alegre, ano 8, $\mathrm{n}^{\circ}$. 16, jul/dez 2006. Disponível em: http://www.scielo.br/pdf/soc/n16/a03n16.pdf. Acesso em: 16 jun 2011.

VERZA, Severino Batista. As Políticas Públicas de Educação no Município. ljuí ed. UNIJUÍ, 2000.

WARAT, Luiz Alberto (Org.). Em nome do acordo: a mediação no direito. Florianópolis: ALMED, 1998.

Boiteux, 2004.

Surfando na pororoca: ofício do mediador. Florianópolis: Fundação

Recebido para publicação: 28/07/2011

Aceito para publicação: 13/12/2011 